\title{
Type 1 Diabetes Management Using Information Communication Technology
}

\author{
Eva Skočir, Tereza Sever, Tadeja Vidmar, Andrej Starc \\ University of Ljubljana, Faculty of Health Sciences, Zdravstvena pot 5, 1000 Ljubljana, Slovenia \\ eva.skocir05@gmail.com; tery.sever@gmail.com; tejci.vidmar@gmail.com; \\ andrej.starc34@gmail.com
}

\section{Abstract}

Introduction: The incidence of diabetes type 1 is increasing. Meanwhile, diabetes represents one of the greatest risks for comorbidity with other diseases and late complications associated with diabetes, thus a great burden for the health system. Diabetes complications occur more often if the disease is poorly managed. Type 1 diabetes is often diagnosed in children and young adults who represent a big part of the working population. Methods: We used the descriptive method with a systematic overview of scientific and professional literature. We searched through CINAHL, Medline, ScienceDirect databases. The key words we searched for were: diabetes type 1, information technology in healthcare, diabetes management, diabetes control, diabetes self-management, disease management, information communication technology and sladkorna bolezen tipa 1 . We typed them into a search engine in various yet meaningful combinations in Slovene and English language. Hundreds of sources of literature have been found. Based on the suitability of the titles a selection was made. Furthermore, based on reading of abstracts, we decided to include 19 sources in preparation of the article. Inclusion criteria when deciding which sources to use were: sources published after 2014; resources that have full access online; available articles for free; professional and scientific literature only; Slovenian and English sources only. The literature search took place in the second half of February and the first half of March 2020. Results: Progress in the field of information and communication technology opens up possibilities for improved health care for patients with diabetes, which is a step toward easier and better diabetes management. Blood glucose monitors continuously measure blood sugar and transmit measurements to the apps on smartphones or directly to the insulin pumps. These pumps then connect to computers where a better overview of the blood sugar status is enabled. Various smartphone applications provide online consultation 
and support for patients. This development creates greater chance for better patient-focused health care. New technologies offer opportunities to overcome barriers, such as geographical distance and lack of access to information that may occur regardless of the patient's age. Discussion and conclusions: Devices such as insulin pumps and various devices for continuous measurement of blood sugar are increasingly interconnecting with each other or with various programmes and applications on PCs and smartphones, therefore allowing individuals a better control of their blood sugar and helping healthcare professionals identify patterns and options in order to help the patient. Technology use is a tool that leads towards decrease of numbers of patients with diabetes complications. Consequently, a higher percentage of individuals that are capable of pursuing their profession are reducing the burden of health care, insurance companies and the state.

Keywords: type 1 diabetes mellitus, healthcare professionals, active working population, technology, diabetes complications

\section{Introduction}

The incidence of diabetes type 1 is increasing (NIJZ, 202O; WHO, 2020). Uncontrolled blood glucose level and uncontrolled diabetes as its consequence, lead to serious damages of various organ systems in the body, especially the nerves and blood vessels (WHO, 2020).

Type 1 diabetes is representing between 5 and $10 \%$ of all diabetes cases in the world. Type 1 diabetes occurs when the production of insulin is deficient. The cause, nor the means to prevent type 1 diabetes are not known. (Tauschmann and Hovorka, 2018; WHO, 2020). Diabetes type 1 is incurable, and lifelong management of the disease is required (Tauschmann and Hovorka, 2018). The management depends upon daily administrations of insulin, frequent blood sugar monitoring and calculating carbohydrate intake (Haslund-Thomsen et al., 2020). Regular glucose monitoring enables appropriate adjustment of the insulin doses and consequently higher chances to achieve normoglycaemia (Nana et al., 2019). Retaining blood glucose within the optimal level significantly reduces the risk of complications. Diabetes complications occur more often if the disease is poorly managed (Haslund-Thomsen et al. 2020). The treatment differs among patients. It depends upon one's habits and characteristics (Rodríguez-Rodríguez et al., 2018).

Diabetes type 1 is often diagnosed in young adults and children, that in time, represent a big part of the working population (Haslund-Thomsen et al., 2020). Meanwhile, diabetes represents one of the greatest risks for comorbidity with other diseases and late complications associated with diabetes, thus a great burden for the health system. The rising number of new cases has become a global problem that, besides public health and health systems, significantly affects also the economy and social development, causing health complications and consequently high costs of therapy (Cerna and Maresova, 2016). 


\section{Methods}

We used the descriptive method with a systematic overview of scientific and professional literature. We searched through CINAHL, Medline, ScienceDirect databases. The key words we searched for were: diabetes type 1, information technology in healthcare, diabetes management, diabetes control, diabetes self-management, disease management, information communication technology and sladkorna bolezen tipa 1 . We typed them into a search engine in various yet meaningful combinations in Slovene and English language. Hundreds of sources of literature have been found. Based on the suitability of the titles a selection was made. Furthermore, based on reading of abstracts, we decided to include 19 sources in preparation of the article. Inclusion criteria were: sources published after 2014; resources that have full access online; available articles for free; professional and scientific literature only; Slovenian and English sources only. We searched also on the official websites of WHO (World Health Organization) and NIJZ (Nacionalni inštitut za javno zdravje RS). The literature search took place in the second half of February and the first half of March 2020.

\section{Results}

In the past, the only option of managing the disease was manual checking of the blood glucose via finger picking and manual administration of the insulin, but in the last years technology has become an indispensable accessory in helping and easing self-management of the disease (Rodríguez-Rodríguez et al., 2018). Elementary way of applying insulin are insulin pens. In 199os insulin pumps became widely available and brought a huge improvement in health care of patients with diabetes. Modernization of insulin pumps has enabled implementation of adjunctive technologies, such as bolus calculators and furthermore combining monitoring blood glucose and applying insulin with interconnected sensors of blood glucose, insulin pumps and diverse mobile applications that are rapidly gaining popularity in last years (Tauschmann and Hovorka, 2018). Even though the therapy with insulin pumps and other devices is on average more expensive than therapy with daily injections, the costs are in long term reduced from fewer diabetic complications that follow improved diabetes control (Beck et al., 2019).

Technology and glucose monitoring

- $\quad$ Blood glucose meters: smaller than in the past; testing blood glucose via finger picking.

- Continuous glucose monitors: provide up to 1440 measurements per day - one measurement per minute; are interconnected with mobile apps and insulin pumps or can transfer data to programmes on computer (Beck et. Al., 2019, Haslund-Thomsen et al., 2020; Rodríguez-Rodríguez et al., 2018). 
Technology and insulin application

- Smart pens and mobile applications: Smart pens can connect with smartphone applications wirelessly and share data. Doses, time, bolus calculation and more can be saved in the app. Smartphone application nowadays offer recording of blood-glucose data, food intake, dose recommendations and tracking of physical exercise.

- Insulin pumps: connected to the patient with a tubing system; enabling continuous delivery of insulin, include bolus calculators; ability to programme multiple basal rates; can connect with a computer and send data to the programme; can connect with mobile applications; malfunctions of pumps and infusion sets may occur.

- $\quad$ Automated insulin delivery systems, often named artificial pancreas consist of continuous glucose monitor, an insulin pump, and an algorithm - using glucose concentration and previous insulin delivery data to regulate insulin delivery (Beck et al., 2019; RodríguezRodríguez et al., 2018).

Progress in the field of information and communication technology opens up possibilities for improved health care for patients with diabetes, which is a step toward easier and better diabetes management (Nana et al., 2019).

Blood glucose monitors continuously measure blood sugar and transmit measurements to the apps on smartphones or directly to the insulin pumps. These pumps then connect to computers. Various smartphone applications provide online consultation and support for patients. This development creates greater chance for better patient-focused health care. New technologies offer opportunities to overcome barriers, such as geographical distance and lack of access to information that may occur regardless of the patient's age (Lanzola, 2016).

Telemonitoring improves control of blood sugar, helps to reduce HbAic. There were found positive effects on associated diseases, such as hypertension, dyspnea, etc. patient empowerment and better quality of life (Andrès et al., 2019; Kitsiou et al., 2017).

\section{Discussion}

Use of ICT is enabling individuals a better control of their blood sugar and helping healthcare professionals identify patterns and options in order to help the patient. Technology use is a tool that leads towards decrease of numbers of patients with diabetes complications. Consequently, a higher percentage of individuals that are capable of pursuing their profession is reducing the burden on health care, insurance companies and the state (Dadgar and Joshi, 2018; Kitsiou, 2017; Krishnan and Selvam, 2019; Murillo, 2017; Offringa, 2018; Wu Y, 2017). 
Only $20 \%$ of patients with diabetes type 1 do not keep any record. Paper documentation is most common among the patients that do keep record, and only $4 \%$ use mobile apps. Reasons for not using apps are: paper documentation preference, considering their use as a waste of time, or considering it too difficult. With the development of technologies, we can expect higher number of users in the future. Besides following blood glucose levels, the treatment of diabetes also involves monitoring one's weight, intake of carbohydrates, insulin dosage, and physical activity (Cerna and Maresova, 2016; Dinath and Mearns, 2019).

To be able to give proper advice about the apps and also type of device that would be the most suitable for a patient, specific information is required: the patient's personality, technical skills, daily regimen, attitude to diabetes, preferences in data visualization and functionalities, willingness to learn new things, and motivational means (Holubová et al., 2019).

\section{Conclusions}

It is necessary to emphasize the important role that diabetic patients have in the development of information and communication technologies. They need to be included in the innovation process, as they are the key actors, that can contribute to the development of health informatics in this field (Kanstrup, 2015).

\section{References}

ANDRÈS E., MEYER L., ZULFIQAR A.A., HAJJAM M., TALHA S., BAHOUGNE T., ERVÉ, S., HAJJAM, J., DOUCET, J., JEANDIDIER, N., ET AL., 2019. Telemonitoring in diabetes: evolution of concepts and technologies, with a focus on results of the more recent studies [online]. Journal of Medicine and Life, vol. 12, no.3, pp. 203-214. Available from: https:// medandlife.org/wp-content/uploads/JMedLife-12-203.pdf

BECK, R.W., BERGENSTAL R.M., LAFFEL L.M., PICKUP J.C., 2019. Advances in technology for management of type 1 diabetes [online]. Lancet, vol. 394, no. 10205, pp. 1265-1273. Available from: https://doi.org/10.1016/ So140-6736(19)31142-0.

CERNA L., MARESOVA P., 2016. Patients' attitudes to the use of modern technologies in the treatment of diabetes [online]. Patient preference and adherence, vol. 2016, no. 10, pp. 1869-1879. Available from: doi: 10.2147/PPA. S118040.

DADGAR M., JOSHI K.D., 2018. The role of information and communication technology in self-management of chronic diseases: an empirical investigation through value sensitive design [online]. Journal of the Association for Information Systems, vol. 19, no. 2, pp. 86-112. Available from: https:// aisel.aisnet.org/jais/vol19/iss2/2. 
DINATH W., MEARNS M., 2019. Choosing an effective mobile health application to help manage Type 1 Diabetes Mellitus effectively [online]. South African Journal of Information Management, vol. 21, no. 1, pp. 1-10. Available from: https://doi.org/10.4102/sajim.v21i1.1050.

HASLUND-THOMSEN H., LAUGESEN B., HASSELBALCH L.A., 2020. Parental experiences of continuous glucose monitoring in danish children with type 1 diabetes mellitus [online]. Journal of pediatric nursing, vol. 53, no. 2020, pp. 149-155. Available from: https://doi.org/10.1016/j. pedn.2020.03.010.

HOLUBOVÁ A., VLASÁKOVÁ M., MUŽÍK J., BROŽ J., 2019. Customizing the types of technologies used by patients with type 1 diabetes mellitus for diabetes treatment: case series on patient experience [online]. JMIR mHealth and uHealth, vol. 7, no. 7: 1-17. Available from: doi: 10.2196/11527.

KANSTRUP A.M., BERTELSEN P., NØHR C., 2015. Patient innovation: an analysis of patients' designs of digital technology support for everyday living with diabetes [online]. Health information management: journal of the Health Information Management Association of Australia, vol. 44, no. 1, pp.12-20. Available from: https://doi.org/10.1177/183335831504400102.

KITSIOU S., PARÉ G., JAANA M., GERBER B., 2017. Effectiveness of mHealth interventions for patients with diabetes: an overview of systematic reviews [online]. PLoS ONE, vol. 12, no. 3, pp. e017316o. Available from: https://doi.org/10.1371/journal.pone.017316o.

KRISHNAN G., SELVAM G., 2019. Factors influencing the download of mobile health apps: Content review-led regression analysis [online]. Health Policy and Technology, vol. 8, no. 4, pp. 356-364. Available from: https://doi. org/10.1016/j.hlpt.2019.09.001.

LANZOLA G., LOSIOUK E., DEL FAVERO S., FACCHINETTI A., GALDERISI A., QUAGLINI S., MAGNI L., COBELLI C., 2016. Remote Blood Glucose Monitoring in mHealth Scenarios: A Review [online]. Sensors (Basel, Switzerland), vol. 16, no. 12, pp. 1983. Available from: https://doi. org/10.339o/s16121983.

MURILLO M., BEL J., PEREZ J., CORRIPIO R., CARRERAS G., HERRERO X., MENGIBAR J.M., RODRIGUEZ-ARJONA D., RAVENS-SIEBERER U., RAAT H., et al., 2017. Impact of monitoring health-related quality of life in clinical practice in children with type 1 diabetes mellitus [online]. Qual Life Res, vol. 26, no. 12, pp. 3267-3277. Available from: 10.1007/ s11136-017-1682-6.

NANA M., MOORE S.L., ANG E., LEE Z.X., BONDUGULAPATI L.N.R., 2019. Flash glucose monitoring: Impact on markers of glycaemic control and patient-reported outcomes in individuals with type 1 diabetes mellitus in the real-world setting [online]. Diabetes research and clinical practice, vol. 157, no. 2019, pp. 1-9. Available from: https://doi.org/10.1016/j.diabres.2019.107893. 
NIJZ, 2020. Sladkorna bolezen [online]. Available from:https://www.nijz.si/sl/ sladkorna-bolezen\#znaki-sladkorne-bolezni.

OFFRINGA R., SHENG T., PARKS L., CLEMENTS M., KERR D., GREENFIELD M.S., 2018. Digital diabetes management application improves glycemic outcomes in people with type 1 and type 2 diabetes [online]. Journal of diabetes science and technology, vol. 12, no. 3, pp. 701-708. Available from: https://doi.org/10.1177/1932296817747291.

RODRÍGUEZ-RODRÍGUEZ I., RODRÍGUEZ J.V., ZAMORA-IZQUIERDO M.A., 2018. Variables to be monitored via biomedical sensors for complete type 1 diabetes mellitus management: an extension of the "on-board" concept [online]. Journal of diabetes research, vol. 2018, no. 3, pp. 1-14. Available from: https://doi.org/10.1155/2018/4826984.

TAUSCHMANN M., HOVORKA R., 2018. Technology in the management of type 1 diabetes mellitus - current status and future prospects [online]. Nature Reviews Endocrinology, vol. 14, no. 8, pp. 464-475. Available from: doi: 10.1038/s41574-018-0044-y.

WHO, 2020. Diabetes [online]. Available from: https://www.who.int/news$\mathrm{room} /$ fact-sheets/detail/diabetes 22.6.2020

WU Y., YAO X., VESPASIANI G., NICOLUCCI A., DONG Y., KWONG J., LI L., SUN X., TIAN H., LI S., 2017. Mobile app-based interventions to support diabetes self-management: a systematic review of randomized controlled trials to identify functions associated with glycemic efficacy [online]. JMIR mHealth and uHealth, vol. 5, no. 3, pp. e35. Available from: doi: 10.2196/mhealth.6522. 